Revista Tecnologia e Sociedade, Curitiba, v. 11, n. 23, 2015

ISSN (versão online): 1984-3526

ISSN (versão impressa): 1809-0044

\title{
Diálogos mediados pelas tecnologias, pelos saberes interculturais e pela competência comunicativa
}

\author{
Dialogues mediated by technologies, by intercultural knowledge and by \\ communicative competence \\ Arlinda Cantero Dorsa ${ }^{1}$ \\ Rosimeire Martins Regis dos Santos ${ }^{2}$ \\ Maria Cristina Paniago Lopes ${ }^{3}$
}

Artigo submetido em jul./2015 e aceito para publicação em jul./2015.

\section{RESUMO}

Este artigo é parte de um trabalho desenvolvida junto ao Grupo de Pesquisas e Estudos em Tecnologia Educacional e Educação a Distância (GETED), da Universidade Católica Dom Bosco (UCDB, Mato Grosso do Sul), que desde 2006 estuda a questão da formação continuada no âmbito presencial e a distância, a linguagem, as inter-relações e as ferramentas de tecnologias de informação e comunicação. Objetiva discutir a importância dos diálogos mediados pelas tecnologias, pelos saberes interculturais e pela competência comunicativa. A metodologia utilizada nessa pesquisa trata-se de um estudo da sociolinguística interacional com abordagem qualitativa. $O$ contexto da pesquisa ocorreu entre professores brasileiros e alunos universitários canadenses em uma parceria de estágio internacional entre a (UCDB) Brasil e a (UOM), no Canadá por meio de encontros presenciais e virtuais. Como subsídio teórico utilizamos Freire (1993), Canale e Swain (1980), Candau (2003), Fleuri (2000/2001). Entendemos que tal parceria evidenciou a necessidade de um diálogo que transpusesse as competências linguísticas e textuais na mediação entre os implícitos interculturais e os saberes necessários.

Palavras-chave: Aprendizagem colaborativa. Tecnologias. Saberes Interculturais. Competência Comunicativa. Brasil. Canadá

\begin{abstract}
This article is part of a work developed with the Group of Research and Studies in Educational Technology and Distance Education (GETED), from the Dom Bosco Catholic University (UCDB, Mato Grosso do Sul), which since 2006 studies the question of continued formation face to face and virtually, the language, the inter-relations and the information and communication tools. It has the objective of discuss the importance of dialogues mediated by technologies, by intercultural knowledge and by communicative competence. The contexto of the research occurred among Brazilian teachers and Canadian university students in a partnership of international internship between (UCDB) Brazil and (UOM) Canada by face to face and virtual meetings. As theoretical support we used Freire (1993),
\end{abstract}

\footnotetext{
${ }^{1}$ Doutora em Língua Portuguesa (PUC-SP), Professora do Programa de Mestrado em Desenvolvimento Local UCDB-MS. Líder do Grupo de Pesquisa em "Patrimônio Cultural, Direitos e Diversidade". Pesquisadora do Grupo de Pesquisas e Estdos em Tecnologia Educacional e Educação a Distância (GETED/UCDB). acdorsa@ucdb.br

${ }^{2}$ Doutora em Educação pela Universidade Católica Dom Bosco (UCDB), período Sanduíche na Universidade de Manitoba, Canadá - Faculty of Human Ecology. Bolsista de Desenvolvimento Tecnológico Industrial do CNPq Nível C. Integrante do Grupo de Estudos e Pesquisas em Tecnologia Educacional e Educação a Distância (GETED/UCDB).profarosimeireregis@hotmail.com

3 Doutora em Linguística Aplicada e Estudos de Linguagem (PUC-SP). Pesquisadora visitante da Universidade de Manitoba, Canadá (Estágio Pós-Doutoral), Department of Family Social Science - Faculty of Human Ecology. Professora do Programa de Pós-Graduação Mestrado e Doutorado em Educação - UCDB. Líder do Grupo de Estudos e Pesquisas em Tecnologia Educacional e Educação a Distância (GETED/UCDB). cristina@ucdb.br
} 
Revista Tecnologia e Sociedade, Curitiba, v. 11, n. 23, 2015

ISSN (versão online): 1984-3526

ISSN (versão impressa): 1809-0044

Canale and Swain (1980), Candau (2003), Fleuri (2000/2001). We understand that the parternship showed the necessity of a dialogue which overpsassed the linguistic and textual competences at the mediation of the intercultural implicits and the necessary knowledge.

Keywords: Coolaborative Learning. Technologies. Intercultural Knowledge. Communicative Competence. Brazil. Canada.

\section{INTRODUÇÃO}

O Brasil e Canadá são duas grandes nações situadas no mesmo continente que se aproximam mais incisivamente em tempos de globalização, como pontuam ou advogam muitos, de acordo com Siqueira (2002, p. 93). Os laços de amizade e de cooperação que permeiam o virtuoso relacionamento histórico de ambos os países é evidente pelo forte dinamismo com que vem se dando os encontros de autoridades brasileiras e canadenses nos últimos anos com cooperação internacional, sobretudo compreendida no âmbito de dois países como Brasil e Canadá.

Com fundamento nessas reflexões, a partir das experiências vividas em um grupo de pesquisas e estudos (GETED) ${ }^{4}$ e de uma parceria entre a Universidade Católica Dom Bosco (UCDB) e a Universidade de Manitoba (UOM) no Canadá, temos experienciado trocas, permutas, diálogos e intercâmbios de saberes entre alunos e professores de ambos locais.

Entendemos a necessidade de uma constante formação linguística cultural para aprender em e com o trabalho coletivo e criar situações de diálogo envolvendo docentes e discentes em uma prática intercultural. Neste sentido, este artigo objetiva discutir a importância dos diálogos mediados pelas tecnologias, pela competência comunicativa e pelos saberes sob a perspectiva intercultural em contexto presencial e virtual.

Por meio de uma parceria entre a Universidade Católica Dom Bosco (UCDB) e a Universidade de Manitoba (UOM), no Canadá, a partir de 2011, iniciou-se um processo de intercâmbio referente ao projeto intitulado: "Estágio de estudantes em

\footnotetext{
${ }^{4}$ Vale ressaltar que o grupo GETED (Grupo de Pesquisa e Estudos em Tecnologia Educacional e Educação a Distância), tem parcerias de colaboração científica com os pesquisadores de algumas Instituições Nacional e Internacional: Universidade Aberta de Portugal; Universidade de Manitoba - Winnipeg, Canadá (Human Ecology), Universidade Federal de Alagoas (Programa de Pós-Graduação em Letras), IFMS - Instituto Federal de Educação, Ciência e Tecnologia de Mato Grosso do Sul - Campus Campo Grande, fato este que possibilita uma socialização das experiências em âmbito micro e macro, promovendo a colaboração científica.
} 
Revista Tecnologia e Sociedade, Curitiba, v. 11, n. 23, 2015

ISSN (versão online): 1984-3526

ISSN (versão impressa): 1809-0044

desenvolvimento internacional com base em comunidades: uma parceria CanadáBrasil". A partir desse convênio, vários estudantes canadenses, estudantes brasileiros e professores envolvidos no projeto, começaram a se relacionar, seja de forma presencial ou virtual ${ }^{5}$, estabelecendo laços afetivos que exigiram esforços de ambos os lados para a aprendizagem da língua e compreensão das diferentes culturas. Esta ação trouxe possibilidades de fortalecer a cooperação entre o Brasil e - Canadá para ações voltadas à educação, inclusive com oferecimento de curso de língua portuguesa para estrangeiros.

Este artigo focaliza parte do projeto maior que aconteceu nos meses de maio a julho de 2012 envolvendo cerca de 12 alunos estagiários canadenses e 5 professores pesquisadores. Desenvolvemos ações pedagógicas e culturais, voltadas não só ao ensino da língua portuguesa, como também às práticas sociais de interação com a comunidade e com a cultura local.

Essas ações nos remeteram à perspectiva intercultural, ou seja, à compreensão da relação homem e cultura e suas implicações nas interações presenciais ou online desenvolvidas, questionadas, descobertas, compreendidas ou reelaboradas.

A metodologia utilizada nessa pesquisa trata-se de um estudo da sociolinguística interacional com abordagem qualitativa, integra em suas análises elementos verbais, não-verbais e sociais, o qual se centra em depoimentos individuais e coletivos, ou seja, ganha relevância, passando a ser entendida como criação conjunta de todos os participantes. Os interagentes levam em consideração não somente os dados contextuais relativamente mais estáveis sobre participantes (...), referência (...), espaço (...), e tempo (...), mas consideram sobretudo a maneira como cada um dos presentes sinaliza e sustenta o contexto interacional em curso (RIBEIRO E GARCEZ, 2002, p.8).

A partir da necessidade dessas reflexões, iniciamos esta discussão enfocando a importância dos diálogos mediados pelas tecnologias, pela competência comunicativa e pelos saberes sob a perspectiva intercultural em

\footnotetext{
${ }^{5}$ Palestra: Blended Learning in Higher Education in Canada: A Promising Practice. Professora Dra. Kathleen Matheos - Universidade de Manitoba, Winnipeg, Canadá. Palestra: Seniors and Information and Communication Technology. Melina Elliott - Master Student University of Manitoba family social science, Winnipeg, Canadá. As palestras foram transmitidas pelo hangout do google com transmissão ao vivo pelo canal do Youtube. Vídeos disponíveis em:

https://www.youtube.com/watch?v=XbBsc6Yobhc

https://www.youtube.com/watch?v=XbBsc6Yobhc\&feature=c4-feed-u
} 
Revista Tecnologia e Sociedade, Curitiba, v. 11, n. 23, 2015

ISSN (versão online): 1984-3526

ISSN (versão impressa): 1809-0044

contexto presencial e virtual, durante o oferecimento de um curso de língua portuguesa oferecido pela UCDB.

\title{
DIÁLOGOS COLABORATIVOS MEDIADOS PELAS TECNOLOGIAS
}

Quando nos relacionamos, seja presencial ou online, encontramos um mundo de conhecimento e cultura diversificada, que às vezes passam despercebidos, os quais deveriam ser um lugar de incentivo para o desenvolvimento individual e coletivo. Sobre este assunto afirma Carvalho (2013, p.410):

\begin{abstract}
O que determina o olhar tem uma origem, depende de certas condições históricas, socioculturais e práticas e, portanto, como todo o contingente, está submetido à mudança e à transformação, dando margem a que seja possível ver de outro modo. Assim, entendemos que o processo de ensino e aprendizagem faz parte da cultura, e que aprendemos envolvendo outros sujeitos nas relações com 0 mundo, considerando seus processos históricos, estabelecendo encontros que potencializem saberes, fazeres, afetos, compartilhando experiências de uns com as experiências dos outros, ou seja, é importante as trocas, o intercâmbio intercultural, parcerias, assim como fortalecimento de pessoas e instituições na construção do conhecimento.
\end{abstract}

Desse intercâmbio entre o Brasil e o Canadá, de encontros interculturais, emergiram interações e diálogos coletivos, colaborativos e compartilhados. A pesquisadora canadense Swain (2001) salienta a importância do diálogo colaborativo e destaca que decorrentes do mesmo, podem surgir processos cognitivos mediadores da aprendizagem entre os pares.

É nesse sentido, que situam nossas inquietações de valorizar e entender diálogos interculturais presenciais ou virtuais, respeitando os saberes de cada sujeito e apostando em práticas colaborativas em um processo permanente de formação.

Defendemos a aprendizagem colaborativa em um contexto intercultural que possibilita aos envolvidos, no nosso caso pesquisadores e alunos, interagir com outros sujeitos, entender e expressar opiniões sobre crenças, práticas culturais específicas, de modo a contribuir com a construção do conhecimento por meio da forma de pensar as vivências, as questões humanas e o enfrentamento das incertezas da própria aprendizagem.

Segundo Ibiapina (2008, p. 37), "a colaboração só se torna evidente em 
Revista Tecnologia e Sociedade, Curitiba, v. 11, n. 23, 2015

ISSN (versão online): 1984-3526

ISSN (versão impressa): 1809-0044

situações dialógicas, isto é, na interação entre pares". Compreendemos a dialogicidade como Freire (1993, p. 43): "Ser dialógico é viver o diálogo". Além disso, "é não invadir ou manipular. Ser dialógico é estar engajado a uma constante transformação da realidade" (FREIRE, 1983, p. 52). Ele adiciona que em qualquer hipótese, a intenção do diálogo é a "problematização do próprio conhecimento em uma realidade concreta, ou seja, entendê-lo melhor, explicá-lo e transformá-lo".

Nós aprendemos a realidade por meio de uma rede de colaboração na qual um ajuda o outro a desenvolver-se ao mesmo tempo em que nos desenvolvemos. De acordo com Freire (1993, p. 9): "Todos aprendem juntos e em colaboração. [...] Ninguém educa ninguém, como tampouco ninguém se educa a si mesmo: os homens se educam em comunhão, mediatizados pelo mundo".

Freire (1993) explana que as pessoas sentem a necessidade de viver em grupos interagindo e estimulando o diálogo, isso faz parte do ser humano e é por esse motivo que o indivíduo estabelece o seu processo de aprendizagem. Portanto, compreendemos que participar de um ambiente de colaboração, intercultural, entre brasileiros e canadenses é, antes de tudo, interligação de dois ou mais sujeitos voltados ao compartilhamento de saberes interculturais, respeitando as diferenças de cada um.

Para que o princípio da colaboração seja efetivado é necessário que haja a construção e a tomada de consciência da identidade pessoal e social, o respeito e a valorização da diversidade quanto às pertenças e opções e à valorização de diferentes formas de conhecimento, comunicação e expressão.

Neste sentido, as interfaces hangout do google plus e facebook, ambas utilizadas no oferecimento do curso de língua portuguesa aos canadenses, possibilitaram novos espaços colaborativos de produção de conhecimento em diferentes lugares e tempos. Além disso, proporcionaram o trabalho em rede, em teias, em grupos, possibilitando a construção de conhecimentos de forma coletiva. Essas interconexões podem representar uma coletividade na criação de vínculos sociais permitindo o encontro e a relação com o outro e objetivando a criação de novos ambientes de interação, socialização e aprendizados'.

\section{SABERES INTERCULTURAIS}


Revista Tecnologia e Sociedade, Curitiba, v. 11, n. 23, 2015

ISSN (versão online): 1984-3526

ISSN (versão impressa): 1809-0044

Sob a ótica das discussões sobre o saber, temos ressignificado um novo olhar para as relações interculturais que, segundo Reinaldo Fleuri a perspectiva intercultural, emerge no:

[...] contexto das lutas contra os processos crescentes de exclusão social. Surgem movimentos sociais que reconhecem o sentido e a identidade cultural de cada grupo social. Mas, ao mesmo tempo, valorizam o potencial educativo dos conflitos. E buscam desenvolver a interação e reciprocidade entre grupos diferentes como fator de crescimento cultural e de enriquecimento mútuo. Assim, em nível das práticas educacionais, a perspectiva intercultural propõe novas estratégias de relação entre sujeitos e entre grupos diferentes. Busca promover a construção de identidades sociais e o reconhecimento das diferenças culturais. Mas, ao mesmo tempo, procura sustentar a relação crítica e solidária entre elas. (FLEURI, 2001, p. 132).

Acreditamos que a variedade de oportunidades de aprendizagem que surgem na convivência com pessoas de outras culturas, encoraja-nos em buscar práticas colaborativas no movimento de interação, oportunizando apropriações construídas em diferentes contextos sócio-históricos. Assim, segundo Fleuri:

\begin{abstract}
A relação entre culturas diferentes, entendidas como contextos complexos, produz confrontos entre visões de mundo diferentes. A interação com a cultura diferente contribui para que uma pessoa ou um grupo modifique o seu horizonte de compreensão da realidade, na medida em que the possibilita compreender ou assumir pontos de vista ou lógicas diferentes de interpretação da realidade ou de relação social (FLEURI, 2000, p.4).
\end{abstract}

Nesse sentido, faz-se necessário esclarecer o que entendemos por contexto intercultural, o qual é pensado a partir da relação entre pessoas de culturas diferentes que atribuem significados diversos às suas ações. Para Walsh (2001, p. 10 - 11), a interculturalidade é "[...] um intercâmbio que se constrói entre pessoas, conhecimentos, saberes e práticas culturalmente diferentes, buscando desenvolver um novo sentido entre elas na sua diferença".

Esta perspectiva da interculturalidade constitui uma tarefa provocadora para esse grupo de brasileiros e canadenses, pois "é necessário ultrapassar uma visão romântica do diálogo intercultural e enfrentar os conflitos e desafios que supõe" (CANDAU, 2003, p.32).

Fleuri (2002, p.17) afirma que a perspectiva intercultural de educação, [...] implica mudanças profundas na prática educativa, de modo a respeitar e integrar a diversidade de sujeitos com os seus saberes, a desenvolver novas metodologias pedagógicas. 
Revista Tecnologia e Sociedade, Curitiba, v. 11, n. 23, 2015

ISSN (versão online): 1984-3526

ISSN (versão impressa): 1809-0044

Compreender isso talvez possa contribuir para que seja dado o devido valor ao aluno em seu ambiente nativo, e que valorize o seu desempenho, experiências, conhecimentos, culturas, identidades nas práticas educacionais.

Nesse pensar, é possível explorar as TIC e Redes Sociais, estabelecendo os diálogos interculturais e o respeito à diversidade cultural, ou seja, respeitar os saberes dos alunos universitários canadenses e estratégias de aprendizagem. Como por exemplo, uma aluna canadense, após uma aula da língua portuguesa, acessou o grupo fechado no facebook ${ }^{6}$, e postou a mensagem: "Maybe we could post our verb conjugations here? Here is the verb "to eat" in present tense (thanks to google translate): Eu como; Você come; Ela/Ele come; Vocês comem; Nós comemos; Elas/Eles comem. Ou seja, a aluna incentivou os demais colegas membros do grupo para destacar a atividade de conjugação de um verbo, propondo uma nova estratégia de aprendizagem e compartilhando sua proposta ao grupo. Uma professora brasileira, comentou a mensagem postando: "Legal! Deu fome." No dia seguinte, durante a aula da língua portuguesa, a aluna canadense queria saber o sentido da palavra legal e quando poderia utilizar a palavra no seu dia a dia no Brasil.

Tal movimento na atividade desenvolvida no facebook, além da possibilidade de pensar estratégias de aprendizagem utilizando as redes sociais, possibilitou ao grupo acompanhar as dúvidas, sugestões, produções dos alunos, além da comunicação e manutenção dos diálogos e desenvolvimento de um senso de pertencimento entre os participantes. O envolvimento do grupo na interpretação das diferentes realidades e contextos pode promover o reconhecimento das diferenças culturais, implicando na busca por novas competências comunicativas.

\section{COMPETÊNCIAS COMUNICATIVAS INTERCULTURAIS}

A palavra competência refere-se ao conhecimento que o falante-ouvinte tem de sua língua. Para Chomsky (1965), é vista como o conhecimento da língua com suas regras e estruturas e o desempenho representa o uso real da língua em situações concretas pois, de acordo com o autor, todo o falante é possuidor de uma competência inata e universal. Esta teoria traz um conhecimento de língua como um

\footnotetext{
${ }^{6}$ O grupo no facebook foi criado em maio de 2011: Aprendizagem Colaborativa Brasil/Canadá. O objetivo do grupo foi fazer um espaço de encontro, interação, diálogo e aprendizagem com seus membros.
} 
Revista Tecnologia e Sociedade, Curitiba, v. 11, n. 23, 2015

ISSN (versão online): 1984-3526

ISSN (versão impressa): 1809-0044

sistema complexo ao conferir a supremacia do código sobre a fala, ou seja, o discurso.

Coube a Hymes (1971) trazer uma nova visão do conceito de competência, apontando para a necessidade de considerar-se no uso da língua, não só o conhecimento das regras e estruturas como também o contexto, incorporando assim a dimensão social da língua e ampliando a noção para competência comunicativa. De acordo com o autor, o usuário da fala ou escrita tem competência quando sabe o que falar, quando falar ou não falar, a quem, com quem e de que maneira falar.

Neste contexto, os aspectos sócio-situacionais e culturais em que ocorre a comunicação verbal que se realiza atendendo aos seguintes aspectos:

1.Linguísticos-gramaticais: compreendendo todos os aspectos gramaticais que vão da fonologia, aos aspectos morfológicos e sintáticos, assim como a questão vocabular e discursiva (textual.

2. Pragmáticos - as habilidades funcionais, interativas e culturais necessárias e que envolvem a prática da linguagem do indivíduo.

Amplia esta visão, ao modalizarem determinadas competências necessárias para a efetivação da comunicação, Canale e Swain (1980) apontando para as competências:

- Gramaticais: habilidades não só no domínio de regras gramaticais como também no reconhecimento de características linguísticas que devem ser utilizadas na formação de palavras ou frases;

- Sociolinguísticas: habilidades na compreensão do contexto situacional e social no qual a língua é utilizada;

- Discursivas: habilidades na construção de enunciados coerentes em um princípio colaborativo com o interlocutor, conectando as estruturas frasais para obter um todo significativo;

- Estratégica: habilidades eficazes de interação, no uso de estratégias de enfrentamento, como compensação ou reparação de imperfeições tanto no conhecimento de regras ou conflitos comunicativos.

Bachman (1990) complementa essa discussão, quando soma a estas competências a habilidade linguística comunicativa, ou seja, o conhecimento e 
Revista Tecnologia e Sociedade, Curitiba, v. 11, n. 23, 2015

ISSN (versão online): 1984-3526

ISSN (versão impressa): 1809-0044

competência aliados à capacidade de colocar em prática o uso da língua de forma adequada e contextualizada.

Alguns fatores socioculturais devem ser considerados ao definirmos contexto nas práticas de linguagem, dentre eles são fundamentais: o papel social e o nível de formalidade dos falantes, conhecimento das variedades linguísticas utilizadas, na linguagem verbal oral e escrita, o conhecimento de mundo, as crenças, os valores, as intenções comunicativas e a competência comunicativa.

Essa mudança de perspectiva causou forte repercussão no ensino de línguas, ao abandonar a visão formal da cultura e dos aspectos socioculturais dos falantes da língua alvo, para tornar-se um instrumento das relações sociais de uma comunidade.

Uma contribuição relevante vem de Maingueneau (2000) quando afirma que a estas competências junta-se uma competência pragmática que contém regras que permitem a interpretação de um enunciado por um sujeito a partir da relação com contexto particular.

Para a efetivação desta competência, as leis do discurso de acordo com Kerbrat-Orecchioni (1986), assumem papel fundamental na relação com o Outro:

-Lei da informatividade- não diga o que o coenunciador já conhece;

-Lei da exaustividade - forneça o máximo de informação pertinente para que interesse ao coenunciador;

-Lei da modalidade - seja claro e econômico nas formulações.

Como se trata de relações sociais de uma comunidade é importante atentar para o pensamento de Bennett (2002), pois segundo ele, quando um membro de uma determinada cultura diferente recebe um determinado enunciado, há necessidade não só de interpretá-lo como também compreendê-lo em uma percepção interativa.

Outra implicação relativa a esta discussão, que envolve a competência comunicativa intercultural, subjaz da necessidade premente de mudança de atitudes para se levar em conta os valores envolvidos nos processos de desenvolvimento da interculturalidade.

La competencia comunicativa intercultural tiene como objetivo que el estudiante se desenvuelva de forma adecuada en cualquier contexto comunicativo y que consiga acceder a otros valores culturales partiendo de su propia identidad cultural, superando obstáculos como el etnocentrismo, los malentendidos, los estereotipos y los prejuicios. La adquisición de esta competencia debe ser un proceso consciente y explícito que conduzca a la adquisición de conocimientos teóricos, al desarrollo de habilidades 
Revista Tecnologia e Sociedade, Curitiba, v. 11, n. 23, 2015

ISSN (versão online): 1984-3526

ISSN (versão impressa): 1809-0044

comportamentales y actitudinales mediante el contacto con la cultura y la lengua meta. (GONZÁLEZ, 2010, p 387).

Sendo assim, é importante enfatizar, que a partir da linguagem, o indivíduo contata com a alteridade, que lhe permite a descoberta do outro e das mais variadas formas de com ele interagir socialmente. Este contato permite-Ihe possibilidades de entender as diferentes culturas, desenvolver valores e atitudes, aprender a aprender, ter adaptabilidade, criatividade, enfim desenvolver uma competência intercultural.

As experiências sentidas no grupo, em nosso contato e nossas práticas linguísticas, trouxeram-nos algumas reflexões pontuais. Inicialmente, pudemos vivenciar nos encontros voltados ao ensino da nossa língua "mãe", que não bastava ensinar as expressões linguísticas comuns na língua portuguesa ou levar os estagiários a dominarem as regras gramaticais para nos comunicar e principalmente, nos interagir.

Nesta interação foram fundamentais as competências sociolinguísticas e estratégicas, pois em nossa comunicação, as práticas culturais exigiam a capacidade para gerar conhecimentos, atitudes, competências para as práticas culturais entre o grupo.

Em um dos nossos encontros, trabalhamos as expressões comuns de cumprimentos e de trato, utilizados por nós brasileiros. Preocupamo-nos em abrir espaço para discussões culturais que exemplificassem os contextos e suas peculiaridades, respeitando as diversidades.

Exemplificando, expressões tais como: "salve, salve"; "que Deus o tenha"; "até mais tarde", "pois não", "daqui a pouco" nos exigia trabalhar a noção do que é explícito e implícito culturalmente, para que houvesse não só o aprendizado da palavra como também ao aprofundamento dos diferentes sentidos dados às palavras, ainda que causasse em muitos momentos estranhamentos.

Além da competência discursiva e estratégica, as leis discursivas de KerbratOrecchioni (1986) foram fundamentais na nossa interação pois exigiam de terminadas qualidades textuais que se fazem presentes como clareza, concisão e objetividade, ao explicarmos o valor referencial das palavras e a implicitude contida que tem uma relação direta com a cultura do brasileiro e o seu famoso "jeitinho".

Outro exemplo interessante está relacionado ao ensino dos verbos modais performativos, ou seja, segundo Neves (1996), nos enunciados modalizados, 
Revista Tecnologia e Sociedade, Curitiba, v. 11, n. 23, 2015

ISSN (versão online): 1984-3526

ISSN (versão impressa): 1809-0044

surgem diferentes significados passiveis de serem atribuídos de acordo com os contextos situacionais e que são advindos da ambiguidade.

No estudo da língua portuguesa, neste encontro presencial ensinamos o uso dos verbos "poder", "querer e "esperar" em diferentes falas interativas em que o contato físico, a entonação, as expressões de afeto, ordem, contrariedade se fizeram presente.

Essas estratégias, além de envolverem mecanismos lexicais, sintáticos e de sequência conversacional em sua condução, demonstram também aspectos ou seja, entonacionais que retratam cordialidade, humildade, pedidos de desculpa, hesitações, subentendidos, ironias, formas de justificativas, polidez ou ordem.

Exemplos dados como: "Empreste-me este caderno"; "Você poderia me emprestar este caderno"; "Eu poderia sair agora?"; "Eu posso sair agora", foram trabalhados no uso dos recursos entonacionais, expressionais e contextuais.

Neste contexto, os nossos interlocutores tinham liberdade de tomar a palavra em intervenções que se reportavam à cultura, às atitudes, aos hábitos, às crenças de cada um deles, buscando entender o sentido pleno das palavras tanto em seu sentido explícito quanto implícito.

O nosso papel enquanto "professor" era não só de levá-los a executar ações, perguntar, ordenar, e sim trabalhar a questão das intenções manifestadas em cada contexto discursivo.

A língua, ferramenta que permite ao homem estabelecer relações entre pessoas, vai sempre ligada a um comportamento comunicativo e a um sistema de significados socioculturais, estabelecidos por códigos verbais e não verbais e pela necessidade nas interações de se preocupar em enfatizar os contextos. Cabe então a seguinte ponderação:

\footnotetext{
Neste contexto complexo onde se cruzam o formal (competência linguística) e o funcional (competência comunicativa), cabe perguntar qual o espaço estratégico que se deverá acionar de modo a capacitar o aluno estrangeiro para se relacionar com a alteridade e estar, assim, preparado para viver e conviver em sociedades complexas e multiculturais.(FIGUEIREDO, 2010, p.167).
}

As experiências vivenciadas junto aos estagiários nos proporcionou uma reflexão profunda sobre a funcionalidade da língua em seus aspectos linguísticos e comunicativos e o papel do contexto como base fundamental para que haja a interação comunicativa intercultural. 
Revista Tecnologia e Sociedade, Curitiba, v. 11, n. 23, 2015

ISSN (versão online): 1984-3526

ISSN (versão impressa): 1809-0044

\section{CONSIDERAÇÕES FINAIS}

Assim, concluímos, mediatizados por uma compreensão da educação como um processo de diálogo entre diferentes grupos sociais e culturais em processo dinâmico de aprendizagem entre culturas e intercâmbio, que houve a construção de um espaço de negociação, trocas, experiências, aprendizagem colaborativa, diálogo intercultural no desenvolvimento do projeto de intercâmbio entre a (UCDB) Brasil e a (UOM), espaço este que promoveu a busca por novas competências linguísticas.

Em razão de a cultura não ser vista de forma homogênea, mas dependente de variáveis dos diversos grupos sociais e da situação contextual, acreditamos que o cenário atual das tecnologias de informação e comunicação puderam nos instigar e ao mesmo tempo nos auxiliar no entendimento de como conceitos tão prismáticos como cultural e interculturalidade podem ser entendidos e apropriados por meio da colaboração e da interação.

A compreensão de outra cultura só é possível se for tomada consciência da própria e da relatividade de ambas. A competência comunicativa intercultural deve permitir a formação de cidadãos disponíveis para viver dentro da sua própria comunidade, em sociedades complexas e multiculturais e, ao mesmo tempo, abertos para a mobilidade e para as novas identidades culturais.

\section{REFERÊNCIAS}

BACHMAN, L. F. Fundamental considerations in language testing. New York: Oxford University Press, 1990.

BENNETT, M. Principi di Comunicazione Interculturale. Milano: FrancoAngeli, Bennett, M. 2002.

CANALE, M.; SWAIN, M. Theoretical bases of communicative approaches to second language teaching and testing. Applied Linguistics, n. 1, p. 1-47, 1980.

CANDAU, V. M. Formação Continuada de professores: tendências atuais. In: CANDAU, Vera Maria (Org.). Magistério: Construção Cotidiana. Petrópolis, Vozes, 2003.

CARVALHO, J. M. Produção cultural e redes de sociabilidade: fluxos de espaço e tempo que atravessam o currículo e o cotidiano escolar. Revista Brasileira de Educação v. 18 n. 53 p. 399-413, 2013. 
Revista Tecnologia e Sociedade, Curitiba, v. 11, n. 23, 2015

ISSN (versão online): 1984-3526

ISSN (versão impressa): 1809-0044

CHOMSKY, N. Aspects of the theory of syntax. Mouton, 1965.

FREIRE, P. Extensão ou comunicação? 7. ed. Rio de Janeiro: Paz e Terra, 1983. Política e educação. São Paulo: Cortez, 1993.

FIGUEIREDO. O. M. A língua como acto e como atitude. Da competência comunicativa às convenções culturais. Limite. Revista de Estudios Portugueses y de la Lusofonía Linguística da Universidade do Porto n. 4, p. 167-180, 2010. Disponível em: http://www.revistalimite.es/volumen\%204/olivia.pdf. Acesso em jun/2013.

FLEURI, R. M. Multiculturalismo e interculturalismo nos processos educacionais. In: CANDAU, V. M. (org.) Ensinar e aprender: sujeitos, saberes e pesquisa. Rio de Janeiro: DP\& $A, 2000$.

FLEURI, R. Desafios da Educação Intercultural no Brasil. In: Revista PerCursos. Florianópolis: Udesc/NEPP, v. 1, n. 2, p. 109-128, 2001.

Intercultura: estudos emergentes. ljuí. Ed: ljuí, 2002.

GONZÁLEZ D. D. M. P. Reflexiones acerca de la competencia comunicativa intercultural en la enseñanza de lenguas extranjeras: Las escuelas oficiales de idiomas, 2010.2 Disponível em: http://www.stes.es/melilla/archivos/libro_diversidad_cultural/Pdfs/Diversidad\%20Cultural\%20 21.pdf. Acesso fev 2013.

HYMES, D. Competência e desempenho em linguística teoria. Aquisição de línguas: Modelos e Métodos. Ed. Huxley e E. Ingram. New York: Academic Press, 1971.

IBIAPINA, I. M. L. M. Pesquisa colaborativa: investigação, formação e produção de conhecimentos. Brasília: Líber Livro Editora, 2008.

KERBRAT-ORECCHIONI, C. L'implicite. Paris: Armand Colin, 1986.

MAINGUENEAU, D. Análise de textos de comunicação. São Paulo: Cortez, 2000.

NEVES, M. H. M. A modalidade: In: $\mathrm{KOCH}$, Ingedore Villaça (Org.). Gramática do português falado. v. 6. São Paulo: Unicamp / FAPESP, p. 163-195, 1996.

RIBEIRO, B. T; GARCEZ, P. M.(orgs). Sociolinguística Interacional. 2. ed. São Paulo: Edições Loyola, 2002.

SIQUEIRA, R. W. B., Diálogos Possíveis. Revista Interfaces Brasil/Canadá, Porto Alegre, v.1, n.2, $2002 . \quad$ Disponível em: <http://www.revistas.unilasalle.edu.br/index.php/interfaces/article/view/828/652>. Acesso em: jun/2013.

SWAIN, M. Integrating language and content teaching through collaborative tasks. The Canadian Modern Language Review, v. 58, n.1, p. 44-63, 2001.

WALSH, C. La educación intercultural en la Educación. Lima: Ministério da Educação, 2001. 